\title{
BMJ Open The impact of an intervention programme employing a hands-on technique to reduce the incidence of anal sphincter tears: interrupted time-series reanalysis
}

\author{
Atle Fretheim, ${ }^{1,2}$ Jan Odgaard-Jensen, ${ }^{1}$ John-Arne Røttingen, ${ }^{1,2}$ \\ Liv Merete Reinar, ${ }^{1}$ Siri Vangen, ${ }^{3,4}$ Tom Tanbo ${ }^{5,6}$
}

To cite: Fretheim A, OdgaardJensen J, Røttingen J-A, et al. The impact of an intervention programme employing a hands-on technique to reduce the incidence of anal sphincter tears: interrupted time-series reanalysis. BMJ Open 2013;3:e003355 doi:10.1136/bmjopen-2013003355

- Prepublication history and additional material for this paper is available online. To view these files please visit the journal online (http://dx.doi.org/10.1136/ bmjopen-2013-003355).

Received 5 June 2013 Revised 3 September 2013 Accepted 23 September 2013

For numbered affiliations see end of article.

Correspondence to Dr Atle Fretheim; atle.fretheim@nokc.no

\section{ABSTRACT}

Objective: To re-evaluate previously published findings from an uncontrolled before-after evaluation of an intervention programme to reduce the incidence of anal sphincter tears. A key component of the programme was the use of a hands-on technique where the birth attendant presses the neonate's head during the final stage of delivery while simultaneously supporting the woman's perineum with the other hand.

Design: Interrupted time-series analysis using segmented regression modelling.

Setting: Obstetric departments of five Norwegian hospitals.

Participants: All women giving births vaginally in the study hospitals, 2002-2008.

Methods: The main data source was the Medical Birth Registry of Norway. We estimated the change in incidence of anal sphincter tears before and after implementation of the intervention in the five intervention hospitals, taking into account the trends in incidence before and after implementation.

Main outcome measures: Incidence of anal sphincter tears and episiotomies.

Results: There were 75543 registered births at the five included hospitals. We found a $2 \%$ absolute reduction in incidence of anal sphincter tears associated with the hospital intervention programme, representing almost a halving in the number of women experiencing serious anal sphincter tears. This is a substantially smaller estimate than previously reported. However, it does represent a highly significant decrease in anal sphincter injuries. The programme was also associated with a significant increase in episiotomies.

Conclusions: The intervention programme was associated with a significant reduction in the incidence of obstetric anal sphincter tears. Still, the findings should be interpreted with caution as they seem to contradict the findings from randomised controlled studies of similar interventions.

\section{ARTICLE SUMMARY}

Strengths and limitations of this study

- Interrupted time-series analysis is probably the most robust method for estimating the effects of an intervention when only observational data are available, such as in this case.

- There may be other explicit or implicit elements of the programme that were equally or more important than the use of manual support techniques, such as the increased use of episiotomies or a higher general awareness about the risk of obstetric anal sphincter injuries.

- To what extent the observed association between the intervention and the reduced incidence of sphincter tears represents a causal relationship is hard to assess, but it seems unlikely that the substantial association observed here can be fully explained by bias due to weaknesses in study design.

\section{INTRODUCTION}

Anal sphincter tears occur in a significant proportion of Norwegian women $(3-5 \%)$ during vaginal delivery, and the incidence has been rising over the last few decades. ${ }^{1}$ It is estimated that between one-third and two-thirds of women with anal sphincter tears suffer from persistent anal incontinence. ${ }^{2}$ Norwegian health authorities launched a national action plan in 2006 to address this problem. ${ }^{3}$ The plan consisted of several action points including changes in the training of midwives and obstetricians, quality assuring the reporting of sphincter injuries and improved management of sphincter injuries. A key objective was to increase the focus on sphincter tears among health professionals.

One of the specific elements in the action plan was to reintroduce a traditional hands-on 
technique where the birth attendant presses the neonate's head during the final stage of delivery, to control the speed of crowning, while simultaneously supporting the woman's perineum with the other hand. The recommendation was largely motivated by observational data showing that anal sphincter injuries occur much more frequently in Norway, Sweden and Denmark than in Finland, where the traditional hands-on technique is more widely used. ${ }^{3}$ This technique was the key element of a multifaceted quality improvement intervention that was implemented first in one hospital in 2005, followed by four hospitals in 2006 and early 2007. Other elements of the intervention were (1) to promote good communication between the delivery assistant and the woman, (2) the use of delivery positions that visualised the perineum during the final stage of delivery, (3) and episiotomy only on indication (lateral or mediolateral episiotomy was the recommended method). ${ }^{45}$

The intervention programme is described in more detail elsewhere. ${ }^{4}{ }^{5}$ Briefly, an experienced midwife from Finland (where the described hands-on technique is widely used) conducted the training during a period of 7-13 weeks at each hospital. All staff members participated and were taught the hands-on technique, first on a pelvic model, then in the clinical setting where the instructor first held her hands on the delivery assistant's hands, and finally with the midwife or doctor delivering themselves under the Finnish midwife's supervision.

In two articles published in 2008 and 2010, the team that developed and implemented the hospital intervention programme reported dramatic reductions in the incidence of anal sphincter tears following programme implementation: "The proportion of parturients with anal sphincter tears decreased from $4-5 \%$ to $1-2 \% . " 45$ The basis for this conclusion was an uncontrolled before-after comparison, which is widely seen as a weak method for establishing cause-effect relationships and estimating effect sizes. A problem with this approach, also acknowledged by the authors of the papers, is that underlying trends in incidence are not adjusted for. It was obvious from the data shown in their publications that the incidence was on the decline before programme implementation. Thus, it seems likely that their beforeafter comparison overestimated the intervention effect.

Owing to our scepticism about the validity of the published effect estimates of the intervention programme and our general interest in having more robust evaluations of large-scale interventions, we sought to conduct a new analysis with a more rigorous methodological approach, that is, an interrupted time-series analysis. This method is often promoted as a reasonable alternative when randomised controlled trials are not feasible for impact evaluation. ${ }^{6} 7$

\section{METHODS}

The project protocol was published on the website of the Norwegian Knowledge Centre for the Health
Services (http://www.nokc.no) and is included as online supplementary file 1 .

For our main analysis, we estimated the change in the incidence of anal sphincter tears before and after implementation of the intervention in the five intervention hospitals, taking into account the trends in the incidence of anal sphincter tears before and after implementation.

In the second analysis, we compared the trends in the incidence of anal sphincter tears before and after the implementation of the technique in the five intervention hospitals, and the incidence of anal sphincter tears in the remaining Norwegian hospitals where the technique has not been actively implemented in routine practice. This analysis also took into account the implementation of local interventions in non-intervention hospitals.

The second analysis should, in principle, provide the most robust effect estimate of the intervention. However, this analysis may underestimate the effect due to partial implementation of similar techniques in nonintervention hospitals. Consequently, we regarded the first analysis as the primary one.

For all births in Norway, a standardised form is completed by the attending midwife or doctor and sent to the Medical Birth Registry of Norway. One item on the form enquires about the presence of perineal rupture (grades 1 and 2), defined as tears in the vaginal mucosa and perineum not affecting the anal sphincter. The next item enquires about sphincter ruptures (grades 3 and 4), defined as a more extensive rupture through parts or all of the anal sphincter and possibly the rectal mucosa.

The Medical Birth Registry provided us with monthly incidence data on anal sphincter tears (grades 3 and 4 injuries) and episiotomies for all hospitals from 2002 to 2008. We also received data on the number of births and the number of caesarean sections. This enabled us to calculate the monthly rates of anal sphincter tears in vaginal births for practically all hospitals in Norway. The registry's data on anal sphincter tears have been validated and found to be reliable. ${ }^{8}$

From the implementers of the intervention, we received information about when the programme was implemented (month and year) for each hospital. We incorporated a 3-4 month transition period after the programme started (ie, the 'interruption' in an interrupted time-series analysis). Data from the transition period were not utilised in our analyses.

In addition, we surveyed all birth facilities in Norway to collect information about local practices and changes in practices regarding hands-on techniques during delivery. The survey findings have been reported elsewhere. ${ }^{9}$

We quantified absolute changes in incidence (levels and trends) across hospitals, with 95\% CIs. The results were weighted based on the number of vaginal deliveries per facility.

Similar analyses were conducted on the use of episiotomy. 
For the statistical analyses, we used repeated measurement techniques with each hospital as the unit of observation (repeated observations for each hospital). More specifically, the analyses were as follows

- Analysis 1 (only intervention hospitals)

The following segmented regression model was specified

$$
\begin{aligned}
\mathrm{Y}(\mathrm{t})= & \beta_{0}+\beta_{1} * \text { preslope }+\beta_{2} * \text { postslope } \\
& +\beta_{3} * \text { intervention }+\mathrm{e}(\mathrm{t})
\end{aligned}
$$

where $\mathrm{Y}(\mathrm{t})$ is the outcome (rate of anal sphincter tears) in time period t. Preslope is a continuous variable indicating the time from the start of the study (coded as 0 , 1,2 , 3, etc). Postslope was coded as 0 up to and including the first point postintervention and coded sequentially from 1 thereafter. Intervention was coded as 0 for preintervention time points and 1 for postintervention time points.

- Analysis 2 (both intervention and non-intervention hospitals)

The following segmented regression model was specified

$$
\begin{aligned}
\mathrm{Y}(\mathrm{t})= & \beta_{0}+\beta_{1} * \text { Ppreslope }+\beta_{2} * \text { Ppostslope } \\
& +\beta_{3} * \text { intervention }+\beta_{4} * \text { Llocalslope } \\
& +\beta_{5} * \text { local }+\mathrm{e}(\mathrm{t})
\end{aligned}
$$

where $\mathrm{Y}(\mathrm{t})$ is the outcome in time period t. Data from intervention hospitals were coded in the same way as in analysis 1 for the variables preslope, postslope and intervention. In addition localslope and local were coded as 0 for intervention hospitals. Postslope and intervention were coded as 0 for all observations from nonintervention hospitals. Preslope was coded in the same way for intervention and non-intervention hospitals. For non-intervention hospitals where a local intervention had been implemented, localslope was coded as 0 up to and including the first point postlocal intervention and coded sequentially from 1 thereafter and local was coded as 0 for prelocal intervention time points and 1 for postlocal intervention time points. For all other non-intervention hospitals localslope and local were coded as 0 .

In the two specified models, $\beta_{1}$ estimates the slope of the preintervention data; $\beta_{2}$ estimates the change in slope postintervention for intervention hospitals; $\beta_{3}$ estimates the change in the level of outcome for intervention hospitals as the difference between the estimated first point postintervention and the extrapolated first point postintervention if the preintervention line was continued into the postintervention phase; $\beta_{4}$ estimates the change in slope as a consequence of locally implemented interventions; and $\beta_{5}$ estimates the change in the level of outcome as a consequence of locally implemented interventions. Analyses were conducted using SAS V.9.2.
In accordance with what was outlined in our protocol, we also ran analyses where we included the launch of the national action plan (January 2006) as an explanatory variable, using a time-varying dummy variable $(0$ before January 2006, and 1 afterwards).

Finally, although our analytical approach is widely used and recommended for analysis of time-series data, ${ }^{10}$ it may be argued that using binomial, logistic or Poisson regression would be more appropriate since we are dealing with a dichotomous outcome, regardless of the presence or not of anal sphincter tears. Logistic and binomial regression models are mainly used for predicting the probability of an outcome at the individual level, while the Poisson approach works well for counts and rates. As our main outcome was the rate of anal sphincter injuries, we ran analyses using a Poisson regression model (based on the log-rates), to test the robustness of our findings.

\section{RESULTS}

From 2002 to 2008, there were 75543 registered births at the five hospitals included in our study, of which $15 \%$ were by caesarean section. The monthly incidence of sphincter tears among the vaginal deliveries at each individual hospital is displayed in figure 1 . The graphical presentation illustrates the challenge with discerning the ongoing trend from a change related to the implementation of the intervention.

The coefficients resulting from the regression analyses are shown in tables 1 and 2. The monthly incidence rates of sphincter tears aggregated across the five hospitals is shown in figure 2, together with the regression lines resulting from our main analysis. The corresponding findings for episiotomy rates are found in figure 3 .

The results for our first analysis (only intervention hospitals) showed a downward trend in sphincter tear incidence at 0.25 percentage points $(95 \%$ CI $0.1 \%$ to $0.4 \%$ ) per year during the preintervention period (see figure 2). Following programme implementation, we observed an immediate $2.1 \%$ absolute reduction in sphincter tear incidence (95\% CI $1.3 \%$ to $3.0 \%$ ). The change in incidence trend following programme implementation was not statistically significant.

The episiotomy rate during the preintervention period was stable at around 15-16\% of vaginal births (see figure 3). The episiotomy rate increased significantly in association with programme implementation in the hospitals, with an absolute change of $10 \%$ (95\% CI $6 \%$ to $14 \%$; see figure 3 ), leading to a postintervention episiotomy rate at around $25 \%$.

The estimated immediate impact of the intervention varied across the five hospitals, with reductions in sphincter tears incidences ranging from 1 to 3 percentage points. Similarly, the increase in episiotomy rate varied from 2 to 16 percentage points.

In our second analysis, we incorporated the incidence rates for all birth facilities in Norway and included 

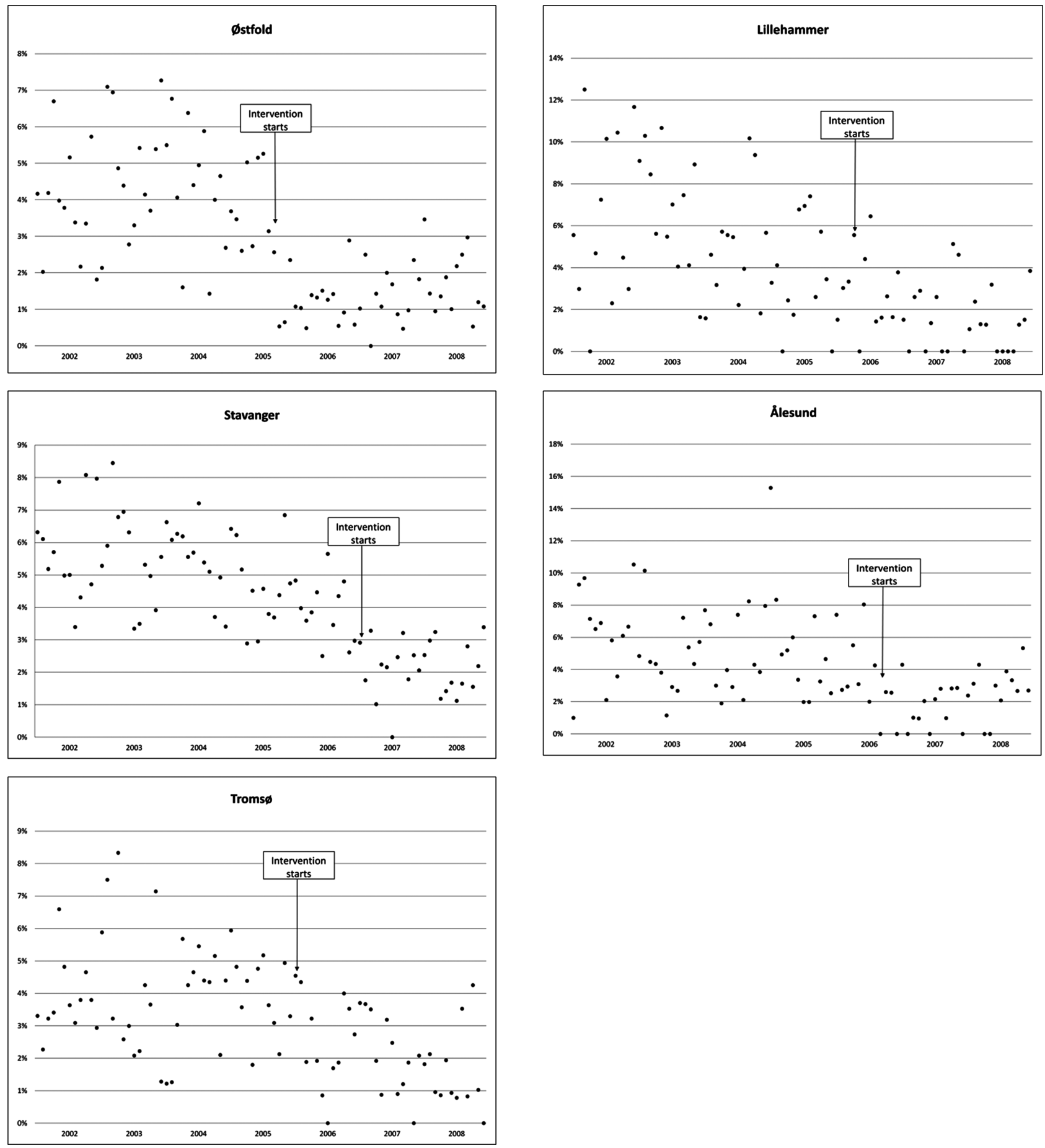

Figure 1 Monthly incidence rates of anal sphincter tears in each of the five intervention hospitals.

adjustments for local interventions based on the data we collected in our survey of Norwegian maternity wards. ${ }^{9}$ Again, we observed a significant reduction in incidence rates associated with implementation of the intervention programme in the five hospitals, though the estimate was smaller than in the primary analysis $(1.2 \%$ absolute reduction: $95 \%$ CI $0.4 \%$ to $2.0 \%$ ). The findings for episiotomy rates were also not substantially different from the main analysis.

The survey findings showed that major changes have taken place in Norwegian delivery wards in recent years so that today the manual techniques are being used as a matter of routine in most places. ${ }^{9}$ In a separate post hoc analysis including only non-intervention hospitals, we detected little or no effect of the locally implemented interventions that had been reported through the survey.

Including the launch of the National Plan as an explanatory variable had little or no influence on our findings, and making use of a Poisson regression approach yielded similar effect estimates as in our main analysis. 
Table 1 Regression coefficients, anal sphincter tears

\begin{tabular}{|c|c|c|c|c|c|c|}
\hline & \multicolumn{4}{|c|}{ Weighted by number of births } & \multicolumn{2}{|c|}{ Unweighted } \\
\hline & Estimate & $95 \% \mathrm{Cl}$ & & p Value & Estimate & p Value \\
\hline \multicolumn{7}{|l|}{ Analysis 1 (only intervention hospitals) } \\
\hline Intercept & 0.054 & 0.048 & 0.059 & $<0.001$ & 0.054 & $<0.001$ \\
\hline Trend preintervention (per year) & -0.0025 & -0.004 & -0.001 & 0.044 & -0.003 & 0.019 \\
\hline Immediate effect of intervention (change in level) & -0.021 & -0.030 & -0.013 & $<0.001$ & -0.024 & $<0.001$ \\
\hline Change in trend postintervention (per year) & 0.000 & -0.004 & 0.005 & 0.899 & 0.002 & 0.449 \\
\hline \multicolumn{7}{|l|}{ Analysis 2 (intervention and non-intervention hospitals) } \\
\hline Intercept & 0.044 & 0.042 & 0.046 & $<0.001$ & 0.035 & $<0.001$ \\
\hline Trend preintervention (per year) & -0.0025 & -0.0030 & -0.0019 & $<0.001$ & -0.0018 & $<0001$ \\
\hline Immediate effect of intervention (change in level) & -0.012 & -0.020 & -0.004 & 0.004 & -0.009 & 0.183 \\
\hline Change in trend postintervention (per year) & -0.000 & -0.005 & 0.005 & 0.921 & 0.001 & 0.747 \\
\hline Immediate effect of local interventions (change in level) & -0.004 & -0.007 & -0.000 & 0.043 & 0.001 & 0.683 \\
\hline Change in trend postlocal interventions (per year) & 0.000 & NA & NA & NA & 0.000 & 0.235 \\
\hline
\end{tabular}

\section{DISCUSSION}

This analysis was motivated by uncertainty regarding previously published estimates on the impact of the hospital-based intervention programme to reduce the incidence of anal sphincter tears. We considered the reported results as unreliable because of serious weaknesses in the study design (uncontrolled before-after comparison). Reportedly, the baseline incidence was between $4 \%$ and $5 \%$, and went down to between $1 \%$ and $2 \%$ due to the hospital intervention programme. We used a more rigorous approach (interrupted timeseries analysis) and arrived at a smaller effect estimate. Still, our revised estimate-an absolute reduction of $2 \%$-is an impressive effect size. Assuming a baseline incidence between $4 \%$ and $5 \%$, our effect estimate represents nearly a halving (between $40 \%$ and $50 \%$ relative reduction) in the number of women experiencing anal sphincter tears. Even if this is considerably less than the $50-80 \%$ relative reduction estimated by the authors in the original publication, our findings may be seen to support their general conclusion: "The multicenter intervention caused a highly significant decrease in obstetric anal sphincter injuries."

An unintended effect of the programme seems to be the substantial increase in the use of episiotomies, despite the recommendation that they should only be performed when clinically indicated. We find it difficult to assess whether the reduced incidence of anal sphincter tears occurred due to or despite the increased use of episiotomies. While it is widely believed that episiotomies can effectively prevent anal sphincter tears if carried out when clinically indicated, a clear consensus about the clinical indications for episiotomy, or what the optimal episiotomy rate is, is lacking. ${ }^{11}$ Routine use of episiotomies, whether midline or mediolateral, is associated with more serious perineal injuries than restricted use; thus, there seems to exist an undefined threshold over which episiotomy rates may contribute to rather than prevent anal sphincter tears. ${ }^{12}$ The baseline episiotomy rate in our study was relatively low $(15-16 \%),{ }^{11}$ but it varied substantially across hospitals. ${ }^{5}$ To our knowledge, no explicit guidelines for when episiotomies should be performed

Table 2 Regression coefficients, episiotomies

\begin{tabular}{|c|c|c|c|c|}
\hline & \multicolumn{4}{|c|}{ Weighted by number of births } \\
\hline & Estimate & $95 \% \mathrm{Cl}$ & & p Value \\
\hline \multicolumn{5}{|l|}{ Analysis 1 (only intervention hospitals) } \\
\hline Intercept & 0.155 & 0.122 & 0.188 & $<0.001$ \\
\hline Trend preintervention (per year) & -0.002 & -0.012 & 0.008 & 0.747 \\
\hline Immediate effect of intervention (change in level) & 0.100 & 0.060 & 0.141 & $<0.001$ \\
\hline Change in trend postintervention (per year) & -0.001 & -0.003 & 0.002 & 0.596 \\
\hline \multicolumn{5}{|l|}{ Analysis 2 (intervention and non-intervention hospitals) } \\
\hline Intercept & 0.202 & 0.193 & 0.210 & $<0.001$ \\
\hline Trend preintervention (per year) & -0.006 & -0.008 & -0.004 & $<0.001$ \\
\hline Immediate effect of intervention (change in level) & 0.087 & 0.056 & 0.118 & $<0.001$ \\
\hline Change in trend postintervention (per year) & -0.010 & -0.029 & 0.009 & 0.312 \\
\hline Immediate effect of local interventions (change in level) & 0.014 & -0.001 & 0.029 & 0.063 \\
\hline Change in trend post local interventions (per year) & 0.000 & -0.000 & 0.000 & 0.112 \\
\hline
\end{tabular}

Numbers in bold indicate $\mathrm{p}<0.05$. 


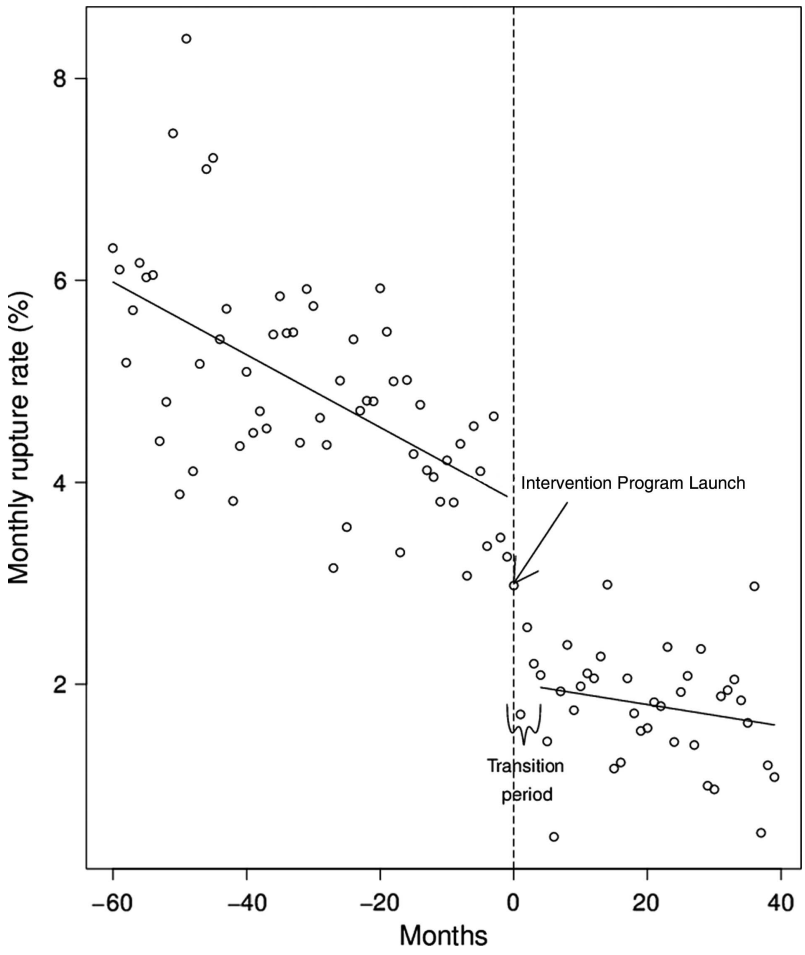

Figure 2 Monthly incidence rates of anal sphincter tears in the five intervention hospitals with fitted segmented regression lines (full model).

have ever been formulated in Norway. Thus, it is practically impossible to assess whether the understanding of

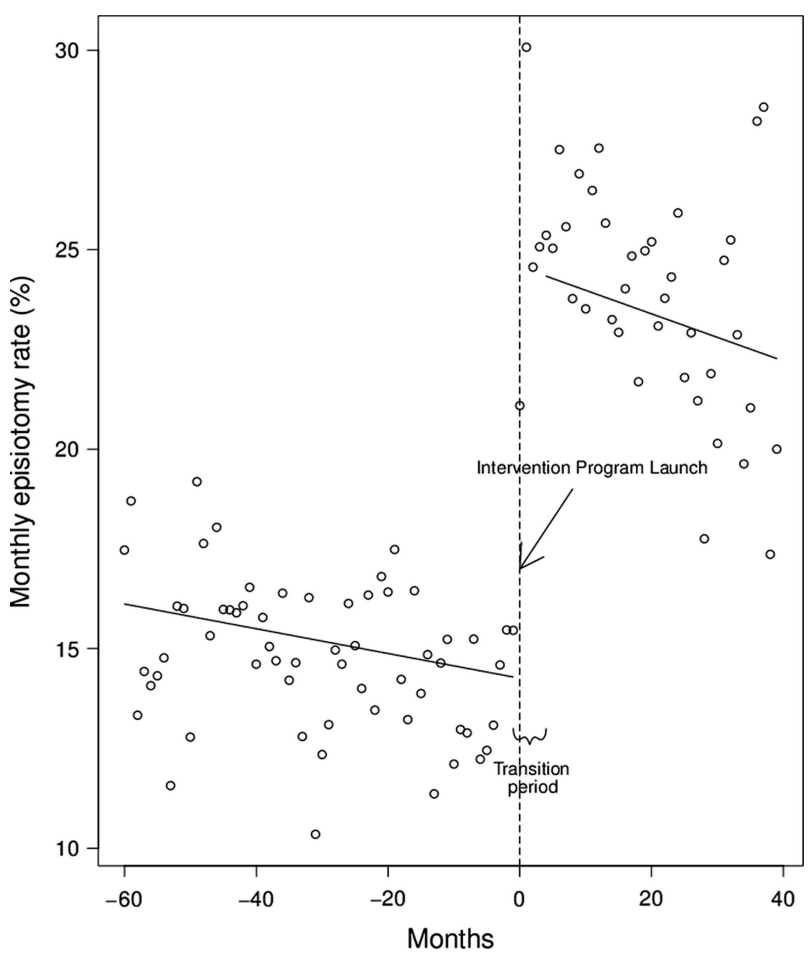

Figure 3 Graphical illustration of the monthly incidence rates of episiotomies in the five intervention hospitals with fitted regression lines (full model). 'clinically indicated' was substantially different within and outside the interventional programme.

One possible weakness of our study is that we did not include any data on the prevalence of risk factors, and whether those changed during the study period. Several factors have been shown to be associated with increased risk of anal sphincter injury, ${ }^{1}$ and it could be relevant to take trends of those into account when assessing the observed changes in the rate of sphincter tears. On the other hand, it seems unlikely that changes in the prevalence of risk factors should occur suddenly and coincide with the launch of the intervention programme in a hospital. The reports did provide some data on risk factors among women who gave birth at the intervention hospitals, ${ }^{5}$ but few significant changes were found when comparing the preintervention and postintervention periods. The only statistically significant changes reported were that, in some hospitals, the proportion of nulliparous women, instrumental deliveries and births where labour was induced, increased. ${ }^{5}$ If anything, this should have contributed to an increase rather than a decrease in the rate of sphincter injuries. ${ }^{1}$

So where do our findings leave us in terms of what impact to expect from implementing a programme like the one evaluated here? Apparently, the programme contributed to a substantial reduction in the number of anal sphincter tears. However, the recognised possible threats to the validity of findings from any interrupted time-series analysis need to be considered, including 'history' (ie, events that coincided with the intervention may have caused the observed change) and instrumentation' (ie, that the data collection method changed when the intervention was launched). ${ }^{6}$ It is possible that the enthusiasm surrounding the programme initiated simultaneous actions that contributed to a reduction in sphincter tear incidence. And lack of blinded assessment of the sphincter injuries may have influenced judgements made by the assessors, as there is some subjectivity involved when sphincter tears are classified. Having said that, it seems unlikely that these or other potential sources of bias can fully explain the substantial association we observed between the intervention programme and reduced incidence of sphincter tears.

An additional challenge with interpreting these findings lies with understanding which component of the intervention programme mediated its effect. The hands-on technique is an obvious candidate, but there may be other explicit or implicit elements of the programme that were equally or more important, such as the increased use of episiotomies or a higher general awareness about the risk of obstetric anal sphincter injuries.

We should also consider how the findings fit in the context of the global body of evidence. Are the findings consistent with what others have found? A recent Cochrane review identified four randomised controlled trials where 'hands-on' techniques were tested against 
more passive approaches. ${ }^{13}$ Contrary to what our analysis suggests, the trial findings do not clearly favour active manual intervention. Moreover, the risk of harm cannot be ruled out: in one of the trials, the authors reported a higher incidence of third-degree perineal sphincter tears among women treated with a 'hands-on method' compared to women treated with a 'hands-poised' approach $(2.7 \%$ vs $0.9 \%$; $<0.05) .{ }^{14}$

\section{CONCLUSIONS}

Although our interrupted time-series analysis produced a smaller effect estimate than earlier evaluations of the same interventional programme, our findings support statements made by the authors of the previous studies, namely that the intervention programme seems to have dramatically reduced the incidence of sphincter tears. Nevertheless, the findings should be interpreted with caution as they seem to contradict the findings from randomised controlled studies of similar interventions. Consequently, more robust evidence is needed to clarify whether interventional programmes using hands-on techniques are likely to reduce the incidence of anal sphincter tears. If such programmes are to be implemented in other settings, this should be performed in a fashion that allows for rigorous evaluation, for example, by randomising hospitals into early and late implementers of the programme.

Author affiliations

${ }^{1}$ Global Health Unit, Norwegian Knowledge Centre for the Health Services, Oslo, Norway

${ }^{2}$ Faculty of Medicine, Institute of Health and Society, University of Oslo, Oslo, Norway

${ }^{3}$ Woman and Children's Division, National Resource Centre for Women's Health, Oslo University Hospital, Oslo, Norway

${ }^{4}$ Department of Chronic Diseases, Norwegian Institute of Public Health, Oslo, Norway

${ }^{5}$ Woman and Children's Division, Oslo University Hospital, Oslo, Norway

${ }^{6}$ Institute of Clinical Medicine, University of Oslo, Oslo, Norway

Acknowledgements The authors would like to acknowledge the services of the Medical Birth Registry of Norway, and particularly of Vernar Sundvor.

Contributors The study was conceived by AF and J-AR. The statistical analyses were conducted by JO-J and AF. LMR, SV and TT contributed to the interpretation of the findings. AF wrote the first draft of the manuscript and received comments from all coauthors. All authors have read and approved the final version of the manuscript.

Funding This research received no specific grant from any funding agency in the public, commercial or not-for-profit sectors.

Competing interests None.
Provenance and peer review Not commissioned; externally peer reviewed.

Data sharing statement The dataset we have based our analyses on was prepared and provided to us by the Norwegian Medical Birth Registry. When handing over data to us, the Registry pointed out that "Although the data are considered to be anonymous, they are more disaggregated than the datasets we usually provide. You therefore need to be cautious with publishing these data to ensure that there is no risk that individuals can be identified" (our translation from Norwegian). Thus, we are reluctant to posting the dataset online.

Open Access This is an Open Access article distributed in accordance with the Creative Commons Attribution Non Commercial (CC BY-NC 3.0) license, which permits others to distribute, remix, adapt, build upon this work noncommercially, and license their derivative works on different terms, provided the original work is properly cited and the use is non-commercial. See: http:// creativecommons.org/licenses/by-nc/3.0/

\section{REFERENCES}

1. Baghestan E, Irgens LM, Børdahl PE, et al. Trends in risk factors for obstetric anal sphincter injuries in Norway. Obstet Gynecol 2010;116:25-34.

2. Dudding TC, Vaizey CJ, Kamm MA. Obstetric anal sphincter injury: incidence, risk factors, and management. Ann Surg 2008;247:224-37.

3. Nasjonalt råd for fødselsomsorg. Sfinkterskader ved fødsel bør reduseres i Norge. Nasjonal handlingsplan [Sphincter injuries related to birth should be reduced in Norway. National action plan]. Oslo: Sosial- og helsedirektoratet, 2006.

4. Laine K, Pirhonen T, Rolland R, et al. Decreasing the incidence of anal sphincter tears during delivery. Obstet Gynecol 2008;111:1053-7.

5. Hals E, Øian P, Pirhonen T, et al. A multicenter interventional program to reduce the incidence of anal sphincter tears. Obstet Gynecol 2010;116:901-8.

6. Shadish WR, Cook TD, Campbell DT. Quasi-experiments: interrupted time-series designs. Experimental and quasi-experimental designs for generalized causal inference. Boston: Houghton Mifflin, 2002:171-206.

7. Fretheim A, Oxman AD, Lavis JN, et al. SUPPORT tools for evidence-informed policymaking in health 18: planning monitoring and evaluation of policies. Health Res Policy Syst 2009; 7(Suppl 1):S18.

8. Baghestan E, Bordahl PE, Rasmussen SA, et al. A validation of the diagnosis of obstetric sphincter tears in two Norwegian databases, the Medical Birth Registry and the Patient Administration System. Acta Obstet Gynecol Scand 2007;86:205-9.

9. Fretheim A, Tanbo T, Vangen S, et al. Use of manual techniques for perineal support in Norwegian maternity departments. Tidsskr Nor Laegeforen 2011;131:2352-4.

10. Wagner AK, Soumerai SB, Zhang F, et al. Segmented regression analysis of interrupted time series studies in medication use research. J Clin Pharm Ther 2002;27:299-309.

11. Graham ID, Carroli G, Davies C, et al. Episiotomy rates around the world: an update. Birth 2005:32:219-23.

12. Carroli G, Mignini L. Episiotomy for vaginal birth. Cochrane Database Syst Rev 2009;(1):CD000081.

13. Aasheim V, Nilsen $A B$, Lukasse $M$, et al. Perineal techniques during the second stage of labour for reducing perineal trauma. Cochrane Database Syst Rev 2011;(12):CD006672.

14. Mayerhofer K, Bodner-Adler B, Bodner K, et al. Traditional care of the perineum during birth. A prospective, randomized, multicenter study of 1,076 women. J Reprod Med 2002;47:477-82. 